\title{
SIGNIFICADOS Y FUNCIONES DE LOS GRABADOS RUPESTRES PREHISTÓRICOS DE ARMAS METÁLICAS EN EL NOROESTE DE LA PENÍNSULA IBÉRICA
}

\author{
Por \\ J. M. VÁZQÚEZ VARELA
}

\section{INTRODUCCIÓN}

Se presenta el estudio de los significados y funciones de los petroglifos de armas al aire libre. Estas son puñales y alabardas, que a veces aparecen acompañadas de un tema cuya naturaleza exacta se desconoce y que convencionalmente se viene denominando escutiforme.

A pesar de la estilización de las representaciones, por sus características tipológicas, se puede considerar que abundan los puñales de espigo y las alabardas del tipo Carrapatas, que por aparecer asociados con cierta frecuencia pueden corresponder al inicio de la Edad del Bronce. Para mayor seguridad y teniendo en cuenta la vida de cada uno de estos tipos y las dificultades de lectura de las figuras se puede establecer un margen de confianza para su datación en un período que abarca desde el final del Calcolítico hasta la mitad de la Edad del Bronce. Muy posiblemente un buen número de representaciones de armas pueden atribuirse al comienzo de la Edad del Bronce (COSTAS, 1997), (VÁZQUEZ, 1999).

La información actual de los motivos presentes en las diferentes estaciones (COSTAS, 1997) se resume en la tabla siguiente:

"CUADERNOS DE ESTUDIOS GALLEGOS", Tomo XLVII, Fascículo 113, Santiago 2000. 


\begin{tabular}{|c|c|c|c|c|}
\hline Municipio & Estación & Alabardas & Puñales & Escutiformes \\
\hline \multirow[t]{10}{*}{ Campo Lameiro } & P. Furada II & & 4 & \\
\hline & P. Furada IV & & 1 & \\
\hline & P. Furada V & & 1 & \\
\hline & Chan da Lagoa XXI & & 1 & \\
\hline & Chan da Lagoa XXIV & & 1 & \\
\hline & Matabois I & & 2 & \\
\hline & Matabois II & & 1 & \\
\hline & Matabois III & & 1 & \\
\hline & Matabois XII & & 2 & \\
\hline & Ramallada، & & 12 & \\
\hline \multirow[t]{3}{*}{ Cangas do Morrazo } & Laxe do Chan & 4 & & \\
\hline & Mogüelos II & & 2 & \\
\hline & Mogüelos III & & & 2 \\
\hline Cotobade & Pedra das Ferraduras & & 2 & 2 \\
\hline \multirow[t]{6}{*}{ Gondomar } & Auga da Laxe I & 6 & 11 & 8 \\
\hline & Auga da Laxe II & 1 & & \\
\hline & Auga da Laxe III & 2 & 5 & \\
\hline & Auga da Laxe IV & 5 & & \\
\hline & Santa Lucia & 3 & & \\
\hline & Silla de la Reina & 1 & & \\
\hline Dumbría & Pedra Ancha & 3 & 2 & 5 \\
\hline Marín & Pornedo I & & 1 & \\
\hline Moraña & Xan de Deus & 1 & & \\
\hline \multirow[t]{2}{*}{ Redondela } & Poza da Lagoa II & 5 & 5 & 1 \\
\hline & Poza da Lagoa III & & 3 & \\
\hline Rianxo & Monte da Pena & 2 & 1 & \\
\hline Santiago & Castriño de Conxo & 4 & 11 & 4 \\
\hline Silleda & Primadorno & 2 & 4 & 1 \\
\hline Valença do Minho & Laxe & & & 2 \\
\hline Vigo & Laxe & & 2 & \\
\hline
\end{tabular}

"CUADERNOS DE ESTUdIOS GALLEGOS", Tomo XLVII, Fascículo 113, Santiago 2000. 
Con anterioridad se han clasificado las estaciones de armas de un modo hipotético en dos grupos, A y B (VÁZQUEZ, 1990, 1999):

El tipo A (VÁZQUEZ VARELA, 1990), se caracteriza por la presencia de un buen número de grabados, a menudo con cierta ordenación o afán compositivo, sobre una cara plana con cierta inclinación en una piedra de grandes dimensiones que goza de buena visibilidad, próxima a alguna vía de comunicación natural y delante de la cual se puede desplegar un colectivo humano numeroso. Dentro de los yacimientos con las características señaladas es posible hacer dos subtipos:

El primero está compuesto por aquellos donde las armas, por su factura muy similar en todas ellas, en cuanto a estilo, técnica y detalles, tales como las dimensiones y proporciones, y por su disposición ordenada, equidistantes y alineadas en la misma dirección, dan la imagen de un conjunto grabado de una sola vez, o bien en un corto número de ocasiones, poco distantes en el tiempo, respetando un plan general de composición. A este grupo pertenece a Auga da Laxe I en Gondomar, Pontevedra (VÁZQUEZ, 1995).

El segundo subtipo está integrado por aquellas estaciones donde faltan algunas de las características citadas. Por ejemplo, que no exista un programa definido, que las piezas estén representadas de distintas formas, las distancias entre ellas sean irregulares, y las direcciones variables, o al menos sin una orientación claramente preferente, con lo que se consigue una sensación de desorden. A este conjunto pertenecen las rocas con grabados del Castriño de Conxo en las inmediaciones de Santiago de Compostela y la de Monte da Pena en Leiro, Rianxo (VÁZQUEZ, 1999).

El tipo B está representado por grabados con un carácter poco narrativo situados sobre una cara horizontal o subhorizontal de una roca de menor tamaño, visibilidad y disponibilidad de espacio en su entorno para un colectivo humano menor que las del grupo anteriormente descrito. Se encuentran ejemplos en Campo Lameiro y O Morrazo, Pontevedra. 


\section{LOS SIGNIFICADOS}

A partir del análisis de los yacimientos en su contexto, y del contraste de diferentes hipótesis interpretativas derivadas de los paralelos históricos y etnológicos, en especial de las sociedades indoeuropeas, se realizan varias lecturas sobre las posibles funciones y significados de los grabados de armas.

\section{A. El prestigio de lo representado: EI metal y los tipos de armas}

Un primer paso del análisis de los grabados de armas permite ver que se han representado objetos metálicos, y dentro de éstos unos tipos muy concretos, aquellos que se puede considerar con seguridad que han podido servir como armas y herramientas a un tiempo, o solamente como armas.

Esta selección, de un número muy reducido y concreto de objetos para ser representados de entre todos los posibles, merece unas reflexiones que pueden permitir entender la lógica de la elección de lo que merece o tiene el interés suficiente para ser objeto de la acción del grabador.

En principio se aprecian varios niveles de selección que se detallan en grado creciente desde la más general hasta la más específica: de materiales, de grupos de artefactos y de tipos concretos.

$1^{\circ}$ Selección de materiales

La comparación de los objetos representados en los grabados con los que aparecen realmente en el resto del registro arqueológico, y de aquellos cuya existencia se puede inferir en función de éstos, permite precisar que del conjunto de artefactos conocidos de piedra, tallada y pulimentada, de cerámica y de metal, y de aquellos cuya existencia se puede suponer con fundamento de causa, como los hechos de materia orgánica tales como madera, hueso, cuero, piel, tendones, pelo, etc, sólo aparecen representados los de tipo metálico.

$2^{\circ}$ De grupos de artefactos

Visto que el primer nivel de selección es el del metal, y antes de considerar sus implicaciones, es posible apreciar, mediante la comparación de los objetos metálicos representados con los conocidos en el resto del registro arqueológico, que no aparecen grabados todos los tipos existentes 
sino que de los varios grupos en que se clasifican éstos tales como herramientas, herramientas-armas, armas y objetos suntuarios sólo aparecen representados dos conjuntos, los denominados herramientas-armas y armas, puñales y alabardas respectivamente, con exclusión de los restantes.

\section{$3^{\circ}$ De tipos}

Un tercer nivel de selección viene dado por el hecho de que dentro de los dos conjuntos anteriormente citados, el de las herramientas-armas y el de las armas no aparecen todos los tipos existentes, sino que sólo aparecen dos muy concretos: arma y herramienta-arma, alabarda y puñal respectivamente.

De los diferentes tipos adscribibles a los grupos citados presentes en el registro arqueológico en sus diferentes manifestaciones tales como hábitats, tumbas, hallazgos descontextualizados, depósitos, etc., sólo algunos muy concretos, los dos citados, se graban en las rocas.

$4^{\circ}$ De proporciones entre los tipos

Aún es posible detectar otro nivel más de selección, y es el que viene dado por la desproporción numérica entre los tipos concretos representados y su abundancia o escasez real en el resto del registro arqueológico. Así pues, aún dentro de los tipos escogidos como convenientes para grabar, algunos están muy representados y otros no, y la proporción de los tipos grabados puede no coincidir con la que existe entre los tipos reales, e incluso en ocasiones se llega a la situación extrema de una inversión de los representados frente a los reales, dándose el caso de que el elemento más escaso en la realidad es muy frecuente en el grabado (VÁZQUEZ, 1999).

Estos principios de selección indican que el realizador de los petroglifos tomó de la realidad de la cultura a la que pertenecía una serie de temas muy seleccionados en función de sus valores. Por tanto la indagación sobre la naturaleza de lo seleccionado y su posible funcionalidad y significado puede ayudar a descubrir los citados valores, ideas y creencias del autor y de la sociedad a la que pertenecía.

En relación al primer principio de selección citado se puede considerar que los objetos de metal, de acuerdo con los datos del contexto arqueológico de sus hallazgos, son un elemento escaso y apreciado. 
Esta escasez de artefactos metálicos frente a la abundancia de los de piedra o de cerámica viene dada por la poca abundancia de los recursos minerales, su concentración en zonas puntuales, y la mayor complejidad de la cadena técnica que implica el proceso de elaboración, que abarca desde la exploración en busca de las minas hasta la conclusión del útil. Los factores expuestos implican un mayor empleo de tiempo, energía, esfuerzo económico y social para proveerse de un bien escaso y a menudo distante y la existencia de un saber muy especializado que muy probablemente, al menos en algunos casos estuvo en manos de un reducido grupo de especialistas. Esto también llevaría implícito el desarrollo de un excedente para negociar con el metal por parte de aquellas comunidades que no disponían de él, o de los conocimientos para trabajarlo, lo cual a su vez lleva al desarrollo de una mayor complejidad económica.

Por lo expuesto se puede considerar que en muchas áreas la posesión de un objeto metálico era algo poco frecuente por su valor, lo cual podía ser tomado en el código de comportamiento social del área como un indicativo de estatus con ciertas posibilidades, al menos las de disfrutar de un objeto que no estaba al alcance de todos.

De todos modos conviene siempre valorar en la medida de lo posible el valor concreto del metal frente a otras manifestaciones en cada área, pues resulta evidente que no cuesta tanto esfuerzo conseguirlo en un territorio donde abunda que en otros donde escasea.

También resulta de interés estudiar las huellas de uso de los artefactos metálicos para saber su función concreta, si fueron útiles de la vida cotidiana, en este caso en que se empleaban, o si eran herramientas-armas con la doble función, o bien sólo armas o si se trata exclusivamente de objetos indicadores de estatus. En el caso que nos ocupa la escasez de conocimientos sobre la práctica de la minería en la época, y de estudios sobre las huellas de uso de los artefactos, impiden pronunciarse con el rigor necesario sobre el tema.

En todo caso, se puede indicar que en varias zonas de la región hay la posibilidad de las fuentes locales de cobre y oro a no mucha distancia de las rocas con grabados de armas, y que el análisis de algunos artefactos metálicos de cobre señala la posibilidad de que hayan sido hechos con menas locales.

El resto de la información arqueológica apunta a que el metal era un bien escaso y preciado en la sociedad de la época. 
Muchos autores, con los que 'estamos al menos parcialmente de acuerdo, consideran la presencia del metal como un indicativo de estatus de cierto rango por parte del usuario, propietario, o difunto al que acompañan estos bienes. Por todo ello se puede suponer que seleccionaron para representar objetos socialmente estimados, cuya posesión o uso indicaba un cierto estatus social.

Un segundo nivel interpretativo puede leerse en el sentido de que se han escogido aquellos tipos que, bien con cierta ambigüedad, como las herramientas-armas que han podido servir para dos fines distintos, como los propios de la vida cotidiana o como instrumento ofensivo, o bien específicamente ofensivos como las armas, son claramente expresivos para indicar la vinculación de lo grabado con el mundo de las armas y por tanto de lo bélico.

En este caso al tratarse de armas metálicas hay que valorar que por estar hechas en un bien escaso y preciado indica, además del gusto por la novedad técnica prestigiosa, la idea de prestigiar y valorar el arma y lo que ella conlleva. Esta se vincula con el mundo de la guerra y el del varón en general, y con el del guerrero en particular.

De hecho los datos arqueológicos indican que cuando es posible establecer el sexo de los hallazgos antropológicos asociados a las armas en las tumbas, aquellas en la mayoría de los casos suelen estar asociadas con varones.

Los datos históricos y etnográficos apuntan en la misma dirección con un reducido número de excepciones. Por todo ello puede entenderse que las representaciones de armas metálicas hacen referencia al mundo de la guerra, del varón en general y del guerrero. En este caso con la representación de armas valiosas quizás se quiera destacar al tiempo la importancia de la actividad bélica en general, o en particular la de la persona representada.

El tercer nivel de selección parece apuntar a la existencia de un código de expresión en el que se valoran de un modo peculiar ciertos instrumentos, que parecen tener mayor valor expresivo e identificativo de la actividad bélica, de su importancia y de la del individuo que porta los citados elementos. Así las puntas de proyectil del tipo Palmela, que aparecen en algunas tumbas sobrepasando en ellas sobradamente el número de puñales, en especial en la Meseta norte, parecen tener menos valor por este hecho, su abundancia, menor tamaño y complejidad técnica, y no son grabadas. 
Un puñal puede tener un mayor valor real, por la acumulación de cobre que supone y los mayores problemas técnicos que encierra su elaboración, por ello dentro de una economía de recursos expresivos se ha optado por aquellos elementos que con más fuerza indican las ideas anteriores. Por otra parte la mayor visibilidad del puñal también apoya esta idea de que la selección de los tipos a este nivel opera en el sentido de emplear aquellos recursos más expresivos del valor del arma metálica y de las actividades y personas vinculadas con su uso.

En todo caso cabe destacar que al lado de esta explicación caben otras como la pura moda imitativa de otras áreas, o la creación de un artista singular que alcanzó prestigio y fue copiado, sin que haya que recurrir a argumentos un tanto economicistas o deterministas, pues la realidad de la moda es algo muy complejo en la que interviene a menudo el espíritu creador secundado por el imitador.

El cuarto nivel es en cierto modo reiterativo del anterior, pues es muy posible que la selección de ciertos útiles refleje aquellos que por diferentes razones gozan de especial prestigio social, y por ello la representación de objetos escasos vendría a destacar con un nuevo elemento expresivo la importancia de lo representado y del contexto en el que se halla la representación. El caso de las alabardas es paradigmático pues si bien en el registro arqueológico los ejemplares seguros son particularmente escasos, en los grabados tienen cierta presencia.

En algunos casos la idea anterior se ve reforzada por la enorme diferencia entre los porcentajes de representación de los diferentes tipos de objetos grabados y de los referentes metálicos reales. Este es el caso de las alabardas que mientras guardan en los grabados un cierto equilibrio con los puñales, en la realidad el número de éstos es francamente superior al de aquellas.

De lo anterior puede deducirse que las representaciones de armas metálicas están aludiendo al mundo del varón, de la guerra, de lo prestigioso y de la jerarquía expresada a través de útiles bélicos. Esta interpretación se ve apoyada por los datos del resto del registro arqueológico, como se comprueba de un modo más claro en las características de los ajuares de las tumbas y de los depósitos.

Los grabados de armas pueden leerse como una alusión metafórica al mundo de la agresión armada y al varón, que es en la mayoría de las sociedades documentadas en los registros etnográficos e históricos el que se encarga de estas actividades. 
Por otra parte el hecho de que se representen exclusivamente objetos metálicos puede considerarse indicativo del prestigio del metal en estas sociedades, donde muy posiblemente su uso marca el estatus del que lo ejerce. En ocasiones como se documenta en los ajuares de las tumbas de esta época en diferentes lugares de Europa (LULL, 1992) los tipos, la calidad y la cantidad, de los objetos metálicos en general y/o de las armas en particular, señalan el estatus del enterrado con las peculiaridades de edad, sexo, función y posición social.

\section{B. La aportación de la etología humana}

El análisis de los grabados desde la perspectiva de la etología humana también resulta provechoso, al menos, para generar hipótesis interpretativas a contrastar por otras ciencias sociales (VÁZQUEZ, 1995).

Este tipo de lectura puede aplicarse a los grabados aislados, o bien, y de un modo especial y más efectivo, a los conjuntos de armas en algunas rocas singulares donde aparecen conjuntos de ellas con un cierto grado de organización. Si han sido grabadas de una vez o en un período de tiempo muy corto puede representar un conjunto de guerreros en un rito de agregación agresivo, con las armas hacia arriba, en posición de mensaje coercitivo de amenaza que al tiempo recuerda rituales de saludo al extraño que llega a un territorio ajeno. Encierra un mensaje doble, ambiguo, en el que se exhiben señales de amistad al tiempo que de afirmación del poderío del grupo relacionadas con el control sobre el propio territorio (EIB-EIBESFELDT, 1993).

Desde esta perspectiva, podrían estar marcando el límite del territorio de una comunidad, o de un grupo concreto, lo cual en algún caso se ve apoyado por su proximidad a las vías de comunicación tradicionales de la zona.

\section{Los grupos de guerreros}

Las investigaciones clásicas sobre los pueblos indoeuropeos han descubierto desde un momento temprano de la investigación la existencia de grupos o cofradías de guerreros (DUMEZIL, 1952, 1985). Recientes estudios particulares sobre el tema han puesto en evidencia instituciones sociales de este tipo en territorios poco estudiados desde esta perspectiva, como el Noroeste de la Península Ibérica, especialmente Galicia y Norte 
de Portugal, que encajan muy bien con las propias del mundo céltico continental e insular y con los pueblos indoeuropeos en general (GARCÍA, 1991). Sus rasgos generales son los siguientes:

Se trata de grupos de guerreros autónomos o integrados en la tribu que a menudo tienen un carácter marginal y practican la caza y la guerra. Esta suele ser de pillaje y de ostentación para adquirir estatus. Están vinculados con una divinidad guerrera a la que ofrecen sacrificios, a veces en lugares sagrados específicos, como grandes rocas en zonas marginales, en la tierra de nadie, en los límites de comunidades, donde se celebran asambleas, fiestas religiosas, ritos iniciáticos y a veces reuniones sociales, administrativas, jurídicas y económicas.

Hay grupos que viven gran parte del año en los lugares marginales donde hacen la guerra, cazan y celebran ritos iniciáticos y otros, y a veces se integran en los poblados bajo la autoridad superior.

Algunos colectivos tienen carácter marginal y antisocial.Así, por ejemplo, en la literatura irlandesa Fión recibe una educación marginal e iniciática, vive al aire libre en la montaña donde caza y lleva un tipo de vida en la que lo bélico se une con lo heróico y lo mágico (GARCÍA, 1991).

Aunque estos rasgos de guerrero se detectan durante la Edad del Hierro en Europa Occidental y bastantes de ellos son comunes a las comunidades de guerreros indoeuropeos, no se puede extrapolar la existencia de este conjunto de rasgos con toda seguridad al final del Calcolítico y comienzo de la Edad del Bronce del territorio que nos ocupa, pero sí es posible usarlos como hipótesis de trabajo para analizar las rocas con grabados de armas y ver hasta que punto pueden reflejarse en ellas algunas de las características citadas.

En algunas rocas se observan un conjunto de atributos que parecen reflejar bien el modelo descrito de comportamiento de los guerreros:

1.- Roca de buen tamaño con grabados de un conjunto de armas que parecen reflejar, de un modo metafórico, mediante la metonimia de la parte por el todo, una reunión de guerreros.

2.- Su posición en una zona marginal con relación a las tierras más aptas para la producción de alimentos que desde la montaña se divisan.

3.- Su posición en un lugar de comunicación, la vía de paso natural del valle a lo más montañoso, marginal e improductivo del territorio. 4.- Zona con posibilidades para la caza y la ganadería.

"CUADERNOS DE ESTUDIOS GALLEGOS", Tomo XLVII, Fascículo 113, Santiago 2000. 
5.- Un área de montaña que puede servir como límite entre las comunidades que se asientan en el fondo de los valles que se divisan desde allí.

Este conjunto de atributos encaja bien con el escenario y las prácticas de las cofradías de guerreros indoeuropeos prerromanos, con el modelo irlandés, en el que incluso se graban temas simbólicos en las rocas, que constituyen lo esencial de los lugares sagrados (GARCÍA, 1991) y con el modelo indoeuropeo en general (DUMEZIL, 1952, 1985). Por ésto se puede considerar que algunas rocas con grabados de armas han podido servir de lugar de reunión de grupos de guerreros como los aludidos.

Teniendo en cuenta lo expuesto y aunque los grabados no estuviesen hechos por gentes de cultura indoeuropea, al menos algunas de sus características generales podrían ser coincidentes con las de ellos.

\section{Los grabados de armas y los diferentes tipos de poder}

El análisis de los temas representados y del estilo empleado por los grabadores permite percibir en general a través de los grabados de armas y sobre todo de algunas estaciones en particular al menos cuatro tipos de poder:

1) El de los autores de los grabados

Muchos de los grabados y en especial de las estaciones singulares muestran un cierto grado de desarrollo, que indica que son el resultado de una cierta experiencia en la expresión de imágenes.

A los diversos recursos estilísticos empleados se une la idea de la conceptualización del espacio natural de la piedra, que implica su elección con una forma y en un lugar concreto y la articulación cuidadosa de los temas, de modo que el conjunto da la idea de una exposición narrativa global integradora de las imágenes.

Desde el punto de vista de la sociología del arte resulta de interés tratar de determinar el papel de los grabadores.

La abundancia de recursos estilísticos y su acertada aplicación, que dan como resultado un conjunto altamente expresivo logrado con un mínimo de recursos técnicos y conceptuales, implica que quienes lo hicieron era gente con oficio, experiencia, destreza y conocimiento, no sólo técnico sino también del valor simbólico de las representaciones.

"CUADERNOS DE ESTUDIOS GALLEGOS", Tomo XLVII, Fascículo 113, Santiago 2000. 
El grado de buen oficio que exige habilidad, un don personal que se puede cultivar sólo en parte, y experiencia, que sí se puede obtener a base de trabajo, implican que el grabado de calidad muy probablemente estuvo al alcance de un número reducido de personas, quienes lo ejercían con cierta continuidad.

Estos atributos suelen ser propios de especialistas, sin que ello implique que tipo de dedicación deben de tener al tema. En numerosas comunidades etnográficas el artista es una persona práctica en este menester, al que se dedica de un modo parcial, y que comparte con el resto de los miembros de su comunidad otros quehaceres más cotidianos, como la producción de alimentos y otros bienes.

En varias culturas etnográficas e históricas, quienes realizan las manifestaciones artísticas de temas simbólicos son personas que de un modo u otro están relacionadas con este mundo, tales como magos, curanderos, chamanes, sacerdotes, etc., lo cual plantea la posibilidad de que los grabadores hayan tenido un estatus de este tipo, especialistas no sólo en el aspecto artístico sino en el religioso, estando los dos estrechamente unidos.

Esta hipótesis que atribuye la autoría de los grabados a este tipo de especialistas refuerza la interpretación tradicional del carácter simbólico, muchas veces religioso, de gran parte de los petroglifos. Si bien esta teoría es algo tautológica, ya que se fundamenta parcialmente en la hipótesis previa de que los grabados son de tipo simbólico, sí tiene cierto valor por cuanto parece fuera de toda duda que las armas también son expresión de una ideología que en algún caso puede ser de tipo religioso.

Existe un cierto número de testimonios de que en diferentes culturas las armas pueden tener una vinculación con el mundo de lo religioso (DUFRENNE, 1997), por lo que ya se ha abordado esta posibilidad para los petroglifos del Noroeste de la Península Ibérica señalándose la posibilidad de que sean exvotos simbólicos o símbolos relacionados con alguna figura religiosa vinculada de algún modo con la guerra. (VÁZQUEZ, 1994, 1999).

La propuesta aquí defendida, la existencia de especialistas religiosos que en el transcurso de un rito graban, tiene paralelos etnográficos abundantes y puede ser apoyada por el posible carácter ritual al que estaban vinculados estos grabados.

El poder de los especialistas en el arte les viene de su relación con el dominio de lo religioso que tratan en beneficio propio y de la comunidad.

"CUADERNOS DE ESTUDIOS GALLEGOS", Tomo XLVII, Fascículo 113, Santiago 2000. 
Esto les da gran fuerza pues en los ritos y en los mitos se explica y mantienen el orden cósmico y social y el experto en religión puede hacer, mantener, rehacer y cambiar el orden social influyendo profundamente en la sociedad y en el dominio de lo político. Su fuerza puede ser enorme pues sus propuestas vienen apoyadas o legitimadas por el más grande de los poderes: el religioso.

2) El mundo del varón

Las armas y las escenas de su exhibición representadas en la roca son muy posiblemente una referencia a la guerra, la cual es propia de los varones en un porcentaje altísimo de sociedades, si bien en algunas de ellas la mujer puede tener un papel de relevancia en la guerra (ALONSO DEL REAL, 1967), (JACOBSON, 1993) o en la caza, aunque casi únicamente de animales menores. Por ello, es muy probable que estas actividades hayan estado en manos de varones, al igual que en otras partes de la Europa del momento, tal como se documenta a través del arte rupestre y los ajuares de las tumbas.

La plasmación de la ideología del varón en la roca puede proclamar, hacer propaganda y legitimar aspectos del orden social en el que se manifiesta su poder de un modo singular (VÁZQUEZ, 1995)

3) El mundo del guerrero

Como un tipo especial de poder, que quizás no alcance a todos los varones, está el del guerrero. La presencia de armas y joyas en algunas tumbas permite pensar que existía algún tipo de jerarquización social vinculada con la guerra en una sociedad donde ésta tenía posiblemente cierto papel. Este modo de legitimar el poder, a través de las armas, está ampliamente extendido en la Europa de la época (LULL, 1992).

De acuerdo con lo anterior en algunas rocas, se exhibiría, independientemente de su función concreta, el poder de los grupos de guerreros.

4) El poder de la comunidad

Los grabados permiten interpretar que en ellos hay mensajes sobre aspectos económicos, sociales, políticos, ideológicos y religiosos de quienes los hicieron. La comunidad que disfruta el territorio proclama en los grabados su identidad y quizás legitima sus derechos sobre él mediante el complejo discurso de sus grabados, en un momento en el que aumentan 
los requerimientos de terreno apto para las faenas agrícolas y ganaderas (VÁZQUEZ, 1999).

Es obvio que en los grabados sólo se manifiestan, o más bien, sólo hemos sido capaces de leer, algunos tipos de poder, y que muchos otros, tales como los vinculados con algunos aspectos de la producción y de la reproducción, están excluidos aquí y en gran medida en el resto de los petroglifos de Europa.

Están ausentes, por ejemplo, indirectamente los mineros y artesanos, pues aunque ellos no estén presentes sí están sus obras, las armas metálicas. y directamente las mujeres. Este sesgo puede explicarse en función de los intereses de los grupos que grabaron la roca que proclaman sus poderes ocultando los de otros, quizás en un intento de legitimar su posición en un mundo cambiante, como lo fue el del Calcolítico y el comienzo de la Edad del Bronce en el que las diferentes fuerzas en colisión pueden haber negociado posiciones usando varios discursos entre ellos como, en este caso, el del arte en el que las armas pueden ser indicativas de su uso para solucionar los conflictos o sólamente tener una función disuasoria y negociadora.

Esta lectura ha de ser contrastada con datos que procedan de nuevos trabajos de campo sobre petroglifos, tumbas y hábitats.

\section{LAS FUNCIONES}

Si aceptamos que estos grabados tenían un valor simbólico se trata de saber la intención con la que se hicieron públicos, en una roca muy escogida, y el conjunto de creencias y valores que expresan los temas.

Para interpretar la función exponemos una serie de hipótesis que tienen en cuenta el significado de los temas representados: Escenario de varios tipos de ritos, los iniciáticos relacionados con el mundo del varón y los de agregación vinculados con guerreros. Quizás hayan podido servir, mediante la alusión metafórica a ellos, como indicador de valores asociados al territorio donde se encuentra la estación.

La idea fundamental es la de que la roca ha sido el soporte para transmitir por sí sola, o bien como escenario o fondo de actividades sociales, iniciáticas y de agregación en sentido amplio, un conjunto de valores y creencias relacionados con las armas y el mundo del varón.

"CUADERNOS DE ESTUDIOS GALLEGOS", Tomo XLVII, Fascículo 113, Santiago 2000. 
Este conjunto de valores y creencias coincide con el que se suele transmitir en los ritos iniciáticos, para pasar de adolescentes a adultos. Es allí donde se comunican conocimientos religiosos y saberes simbólicos y prácticos relacionados con el nuevo estatus al que se va a acceder.

Los temas grabados, han podido actuar como símbolos o como instrumentos nemotécnicos para reforzar la idea y apoyar la memoria. Su explicación serviría a la hora de exponer estos valores a la comunidad de iniciados.

Esta hipótesis se ve avalada por el hecho de que en las rocas se contiene la ideología del varón y del guerrero, y porque algunas por su posición geográfica en un emplazamiento de buena visibilidad que domina un espacio relativamente llano, donde puede acomodarse con holgura un colectivo más o menos numeroso sin perder de vista los temas grabados, disponen de un escenario apto para rituales de agregación.

Hay abundante información etnográfica e histórica sobre la celebración de ritos iniciáticos y de agregación de guerreros en lugares marginales, lejos de los puntos más frecuentados en la vida cotidiana. En este caso la situación de los grabados en un área alejada de los campos de cultivo en el monte, reúne las características de algunos de los lugares de iniciación, distantes del ager, el lugar de la zona donde se hace palpable la cultura a simple vista y se instala en el saltus, el dominio de la naturaleza, de lo salvaje, el espacio tan usual en las manifestaciones religiosas (GARCÍA, 1991).

De acuerdo con estos datos y consideraciones y en el estado actual de la investigación, cabe señalar que no se pueden dar por seguras algunas de las características de los lugares de iniciación y de agregación de guerreros, pero también es claro que sí aparecen otras. Así pues se puede considerar como una hipótesis probable el que algunas rocas hayan sido en algún momento de su historia testigo de la celebración de rituales iniciáticos y de agregación de los guerreros.

Es posible que la función anterior se complementase con la de límite del territorio, e indicativa de alguna restricción para el acceso o uso de los recursos de la zona a determinados grupos de gente. 


\section{BALANCE}

Posiblemente en las rocas con grabados de armas metálicas se expresa la ideología de la guerra, legitimadora, de algún tipo de poder, y de la comunidad de guerreros, que en ellas pueden celebrar rituales de iniciación y de agregación, posiblemente con mayor valor religioso que secular.

Metafóricamente, pueden representar a toda la comunidad a la que pertenecen los guerreros, y servir como señal de la identidad del grupo, y de marco de referencia sobre los límites de uso del territorio.

En los grabados se percibe la existencia de poderes vinculados con la religión, el mundo del varón, el de los guerreros y la comunidad.

Si bien representa valores característicos del comienzo de la Edad del Bronce, ampliamente documentados en otras áreas de Europa en el arte y el registro arqueológico, tales como el mundo del varón y de la guerra, puede que éstos no sean una novedad por haber existido ya en el período inmediatamente anterior. En este caso lo realmente novedoso sería la expresión de estas ideas mediante los grabados de armas metálicas al aire libre.

Sólo la labor de prospección intensiva de las comarcas, a las que pertenecen los grabados, para localizar los yacimientos arqueológicos sincrónicos con ellos, y su posterior excavación permitirá situarlos en un contexto definido, sin el cual las ideas aquí expuestas no dejaran de ser hipótesis a la espera de poder ser contrastadas. Urge por ello continuar la labor de contextualización histórica del arte rupestre para lograr un mayor grado de comprensión de sus funciones y significados.

\section{BIBLIOGRAFÍA}

ALONSO DEL REAL, C.: 1967 Realidad y leyenda de las Amazonas. Espasa-Calpe. Madrid.

COSTAS GOBERNA, F. J., HIDALGO CUÑARRO, J.M., NOVOA ÁLVAREZ, P. y PEÑA SANTOS, A.: 1997 «Las representaciones de armas en el grupo galaico de arte rupestre», en COSTAS GOBERNA, F. J. y HIDALGO CUÑARRO, J.M. (Eds) Los motivos de fauna $y$ armas en los grabados prehistóricos del continente europeo. Asociación Arqueológica Viguesa. Vigo.

"CUADERNOS DE ESTUDIOS GALLEGOS", Tomo XLVII, Fascículo 113, Santiago 2000. 
DUFRENNE, R.: 1997 La Vallée des Merveilles et les mythologies indoeuropéennes. Studi Camuni. Volume XVII. Capo di Ponte.

DUMEZIL, G.: 1952 Les dieux des Indo-Européens. Presses Universitaires de France. Paris.

- 1985 Heur et malheur du guerrier. Flammarion. Paris.

EIB-EIBESFELDT, I.: 1993 «Biología del comportamiento humano». Manual de Etología Humana. Alianza Editorial. Madrid.

GARCÍA FERNÁNDEZ-ALBALAT, B.: 1990 Guerra y religión en la Gallaecia y la Lusitania Antiguas. Ediciós do Castro. Coruña.

JACOBSON,J.: 1993 The Deer Goddess of Ancient Siberia. A study in the Ecology of Belief. E.J. Brill. Leiden.

LULL, V., GONZALEZ, P. y RISCH, R.: 1992 Arqueología de Europa, 2250-1200 A. C. Una introducción a la «Edad del Bronce». Síntesis. Madrid.

VÁZQUEZ VARELA, J. M.: 1994 Ritos y creencias en la Prehistoria gallega. Xuntanza Editorial. La Coruña

- 1995 Antepasados, guerreros y visiones. Diputación Provincial de Pontevedra. Pontevedra.

- 1999 Ideología, imagen y sociedad en el inicio de la Edad del Bronce en la provincia de A Coruña. Diputación Provincial de A Coruña. La Coruña. 